\title{
HEMOCHROMATOSIS: A RARE CASE REPORT
}

\author{
B. S. Satish Prasad ${ }^{1}$
}

\section{HOW TO CITE THIS ARTICLE:}

B. S. Satish Prasad. "Hemochromatosis: A Rare Case Report". Journal of Evolution of Medical and Dental Sciences 2015; Vol. 4, Issue 03, January 08; Page: 493-495, DOI: 10.14260/jemds/2015/73

ABSTRACT: Hemochromatosis is characterized by a progressive increase in total body iron stores with abnormal iron deposition in multiple organs. MRI is the most sensitive and specific imaging modality in the diagnosis of hemochromatosis.(1) We report the MRI findings of a rare case of secondary hemochromatosis in a patient with cirrhosis.

INTRODUCTION: Hemochromatosis is a pathologic state of intracellular iron accumulation in parenchymal tissues. It can be classified as primary when it originates from genetic disturbance that promotes increase in iron absorption. Secondary causes may be due to chronic disease or multiple blood transfusions.(1) The disease is often clinically silent, but can be diagnosed by MR imaging.

CASE REPORT: A 48 year male patient who is a chronic alcoholic and a known case of chronic liver disease presented to our department for MRI. MRI revealed the following; diffuse loss of signal intensity in the liver and spleen suggestive of iron deposition with evidence of irregular and nodular surface of liver suggestive of liver cirrhosis

Fig. 1: Axial and coronal MRI showing nodularity of liver outline suggestive of cirrhosis and a low signal intensity of liver and spleen that is due to iron overload.
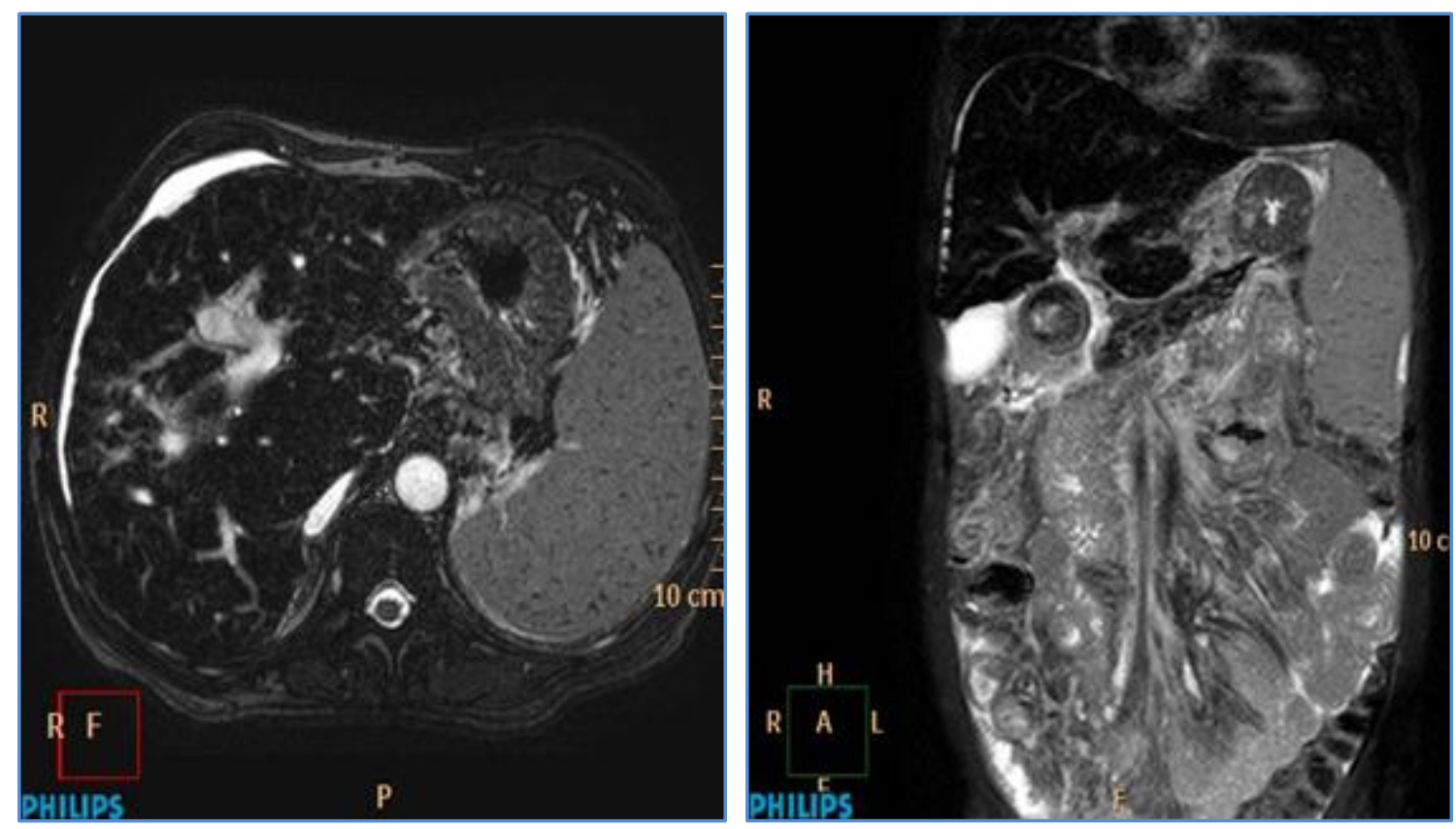

\section{Fig. 1}




\section{CASE REPORT}

DISCUSSION: Hereditary hemochromatosis is a recessive autosomal genetic disorder that alters a protein involved in the regulation of iron absorption.

Patients with hereditary hemochromatosis may be asymptomatic or may present with generalized weakness. Symptoms usually begin between $30 \& 50$ years but can occur much earlier in life.

Early symptoms include severe fatigue (74\%), impotence (45\%), and arthralgia (44\%); fatigue and arthralgia are the most common symptoms prompting a visit to a physician. The most common signs at the time of presentation are hepatomegaly (13\%), skin pigmentation, and arthritis.(2)

CT and MR imaging can be used to detect iron overload. Non enhanced CT shows homogenous increase in attenuation of hepatic parenchyma to $72 \mathrm{HU}$ or more.(3) On MR, loss of signal intensity in affected organs is proportional to iron deposition.

T2-weighted gradient echo images are most sensitive to magnetic susceptibility artifact and thus are the best sequences to detect increased iron deposition in the liver.

Most patients with primary hemochromatosis do not have involvement of the spleen; iron deposition in primary hemochromatosis occurs in the parenchymal cells of the liver (hepatocytes), hence splenic signal intensity usually is normal in these patients where as in secondary hemochromatosis, iron deposition occurs in reticulo endothelial system (Kupffer cells and spleen).(4)

\section{DIFFERENTIAL DIAGNOSIS:}

\section{For secondary Hemochromatosis:}

a) Cirrhosis.

b) Myelodysplastic syndrome.

c) Exogenous increase by ingestion.

d) Parenteral infusion or multiple transfusions.

e) Anemias related to ineffective erythropoiesis like thalassemia.

CONCLUSION: Iron overload is a disease with various causes. Knowledge of imaging findings, patterns of distribution and associated disease can facilitate diagnosis. MR imaging is the best noninvasive method for measuring the level of iron in the liver for the purpose of confirming diagnosis, determining severity and monitoring the therapy with high sensitivity, specificity and positive predictive values.(5)

\section{REFERENCES:}

1. Marcony Queiroz-Andrade, Roberto Blasbalg.MR Imaging findings of iron overload. Radiographics 2009; 29: 1575-1589.

2. Siegelman ES, Mitchel DG, Semelka RC. Abdominal iron deposition: metabolism, MR findings, and clinical importance. Radiology 1996; 199: 13-22.

3. Guyander D, Gandon Y, Deugnier Y. Evaluation of Computed Tomography in the assessment of liver iron overload:a study of 46 cases of idiopathic hemochromatosis. Gastroenterology 1989; 97: 737-743.

4. Westphalen AC, Qayyum A, Yeh BM, et al. Liver fat: effect of hepatic iron deposition on evaluation with opposed phase MR imaging. Radiology 2007; 242: 450-455. 
5. Alustiza JM, Artetxe J, Castiella A. MR quantification of hepatic iron concentration. Radiology 2004; 230: 479-484.

\section{AUTHORS:}

1. B. S. Satish Prasad

\section{PARTICULARS OF CONTRIBUTORS:}

1. Professor and HOD, Department of Radio Diagnosis, Adichunchanagiri Institute of Medical Sciences.

\section{NAME ADDRESS EMAIL ID OF THE CORRESPONDING AUTHOR:}

Dr. B. S. Satish Prasad,

214/Y, $3^{\text {rd }}$ Block, 53 ${ }^{\text {rd }}$ Cross,

$13^{\text {th }}$ Main, Rajajinagar,

Bangalore-560010.

E-mail: satishprasad.bs@gmail.com

Date of Submission: 23/12/2014.

Date of Peer Review: 24/12/2014.

Date of Acceptance: 31/12/2014.

Date of Publishing: 07/01/2015. 